\title{
Oral health-related quality of life and associated factors in the elderly: a population-based cross-sectional study
}

\author{
Qualidade de vida relacionada à saúde bucal e fatores associados \\ em idosos: um estudo transversal com amostra representativa
}

\author{
Jaqueline Colaço (https://orcid.org/0000-0003-3504-8402) ${ }^{1}$ \\ Francisco Wilker Mustafa Gomes Muniz (https://orcid.org/0000-0002-3945-1752) ${ }^{2}$ \\ Damieli Peron (https://orcid.org/0000-0002-7808-238X) ${ }^{1}$ \\ Milena Giotti Marostega (https://orcid.org/0000-0001-6483-3309) ${ }^{1}$ \\ Jéssica Jardim Dias (https://orcid.org/0000-0002-3589-6738) ${ }^{1}$ \\ Cassiano Kuchenbecker Rösing (https://orcid.org/0000-0002-8499-5759) ${ }^{3}$ \\ Paulo Roberto Grafitti Colussi (https://orcid.org/0000-0002-9351-6959) ${ }^{4}$
}

${ }^{1}$ Faculdade de Odontologia, Universidade de Passo Fundo (UPF). R. Gonçalves Chaves, 457. 96015-560 Pelotas RS Brazil. muniz.fwmg@ufpel.edu.br ${ }^{2}$ Departamento de Periodontologia, Universidade Federal de Pelotas. Pelotas RS Brazil. ${ }^{3}$ Departamento de Periodontologia, Universidade Federal do Rio Grande do Sul. Porto Alegre RS Brazil.

${ }^{4}$ Departamento de

Periodontologia, UPF. Passo Fundo RS Brazil.

\begin{abstract}
This study aimed to evaluate the oral health-related quality of life (OHRQoL) and associated factors in the elderly. A cross-sectional study was conducted with 287 elderly of Cruz Alta, Brazil. The following variables were collected: age, sex, ethnicity, level of education, marital status, retirement, medical/dental history, smoking/alcohol exposure, oral hygiene habits, use and need of dental prosthesis, missing teeth, temporomandibular disorder symptoms (TMD), nutritional status, and halitosis. OHRQoL was assessed by Oral Health Impact Profile-14 (OHIP14). The sample was categorized into low impact (sum scores $\leq 6$ ) and high impact (sum scores $\geq 7$ ). Associations were analyzed by Poisson regression with robust variation. Mean scores of OHIP-14 was 5.92 \pm 8.54 . Divorced individuals and those who did not use dental floss presented $77 \%$ and $54 \%$, respectively, higher prevalence ratio (PR) of having higher OHRQoL impact. Elderly that did not need dental prosthesis demonstrated a lower impact on OHRQoL $(P<0.01)$. Elderly with TMD presented a higher $P R$ of having higher OHRQoL impact $(P<0.01)$. It was concluded that higher impact on OHRQoL was associated with marital status, non-users of dental floss and those with TMD. No need dental prosthesis were associated with lower impact on OHRQoL.
\end{abstract}

Key words Dentistry, Psychosomatic Medicine, Quality of life, Risk factors
Resumo O estudo avaliou a qualidade de vida relacionada à saúde bucal (QVRSB) e fatores associados em idosos. Estudo transversal foi realizado em 287 idosos de Cruz Alta, Brasil. As seguintes variáveis foram coletadas: idade, sexo, etnia, nivel educacional, estado civil, aposentadoria, histórico médico/odontológico, exposição ao fumo/ álcool, hábitos de higiene oral, uso e necessidade de prótese, dentes ausentes, sintomas de desordem temporomandibular (DTM), estado nutricional e halitose. QVRSB foi avaliada pelo OHIP-14 (Perfil de Impacto de Saúde Bucal) e categorizado em baixo impacto (soma dos escores $\leq 6$ ) $e$ alto impacto (soma dos escores $\geq 7$ ). Associações foram avaliadas por regressão de Poisson com variância robusta. A média OHIP-14 foi 5,92士8.54. Indivíduos divorciados e aqueles que reportaram não usar fio dental apresentaram $77 \%$ e 54\%, respectivamente, maior razão de prevalência $(R P)$ de terem maior impacto na QVRSB. Idosos que não necessitam próteses dentárias demonstraram menor impacto na QVRSB $(P<0,01)$. Além disso, idosos com DTM apresentaram maior RP de terem maiores escores de OHIP-14 $(P<0,01)$. Foi concluído que maiores impactos na QVRSB estão associados com estado civil, não uso de fio dental e DTM. Não necessitar de prótese dentária esteve associado com menores impactos na QVRSB.

Palavras-chave Odontologia, Psicometria médica, Qualidade de vida, Fatores de risco 


\section{Introduction}

It is well established that the elderly are more susceptible to new and repetitive episodes of oral diseases ${ }^{1}$. On the other hand, dental practices should be conducted in order to reduce the consequences of these oral diseases and promote strategies for oral health maintenance, of which may enhance quality of life $\mathrm{e}^{2}$. This is very important especially when it takes into account the demographic burden of the human aging, as the life expectance is increasing in the last decades, which is observed also in Brazil ${ }^{3}$.

Oral health-related quality of life (OHRQoL) is a multidimensional construction that involves subjective evaluation of oral health, functional limitation, pain, discomfort, physical disability, psychological disability, social disability, and handicap ${ }^{4}$. The literature shows that sociodemographical factors, such as low level of education, female sex, and marital status, may be related to higher impact on $\mathrm{OHRQOL}^{5-7}$. Additionally, the same trend of results is demonstrated in smokers?.

In the last oral health survey conducted in Brazil, poor oral health conditions in the elderly was demonstrated, which included high mean tooth loss, poor gingival health, and high percentage of dental prosthesis need ${ }^{8}$. These conditions were also demonstrated in other cross-sectional studies conducted in southern cities of Brazil $^{9,10}$. In fact, the literature shows that elderly with lower number of teeth ${ }^{11,12}$, lower frequency of toothbrusing ${ }^{11}$, temporomandibular disorders $^{13}$, and periodontitis ${ }^{14}$ have the highest impact on OHRQoL. It was demonstrated that, among the edentate older people, the quality of the denture is significantly associated with lower impact on OHRQoL ${ }^{15}$. Additionally, individuals that received oral rehabilitation presented significant improvements in their OHRQoL ${ }^{16}$. Despite of that, other studies have demonstrated a low impact on OHRQoL, even in the presence of higher prevalence of oral diseases ${ }^{10,14}$.

Epidemiologic studies that assess the process of human aging are very important, especially when evaluating the oral health impact and its consequences in the elderly. Moreover, the literature are scarce about the OHRQoL and associated factors of the elderly, using a representative sampling ${ }^{15,17}$. Therefore, the present study aimed to evaluate OHRQoL and associated factors, such as demographical, socioeconomical, behavioral, and oral variables, in the elderly of a Brazilian southern city. The null hypothesis of this study is that there are no statistically significant differences on OHRQoL in relation to demographical, socioeconomical and oral variables in the elderly.

\section{Material and methods}

\section{Study design and location}

This is a home-based cross-sectional study that interviewed and examined elderly, aged 65 to 74 years, in the urban area of Cruz Alta, a city located in the north region of the Rio Grande do Sul state, Brazil. The city presents 62,821 inhabitants ${ }^{18}$, of which more than $95 \%$ lives in the urban area. From those, 3,730 are aged between 65 to 74 years, and $42 \%$ and $58 \%$ are male and female, respectively. In 2010, the Gini Index was $0.5419^{19}$. The present study was revised and approved by the Ethical Committee of the University of Passo Fundo. All elderly read and signed the informed consent form prior to their participation in the study.

\section{Sample size calculation and sampling strategy}

The formula used for sample size calculation was: sample size $=$ standard normal variate $^{2} \mathrm{x}$ outcome prevalence $\mathrm{x}(1-$ outcome prevalence) / absolute error ${ }^{2}$. We assumed a type error of 5\% (standard normal variate of 1.96) and an absolute error of $5 \%$. The estimated outcome prevalence used was the prevalence of OHIP-14 impact of $20 \%$, as previously reported ${ }^{15}$. OHIP- 14 impact is defined as the prevalence of the answer "always" or "repeatedly" to at least one question. Therefore, the total number of individuals necessary was 246 . Due to attrition rate, we added $15 \%$ of individuals in the final sample, and a total of 283 was estimated.

The sampling strategy is described in detail elsewhere ${ }^{20}$. A probabilistic sample, per cluster, was conducted in order to visit 300 households. The city is composed of 68 districts and neighborhoods, that were dived in five areas, and numbered 0 to 4 , according to the number of inhabitants of elderly in each neighbor and the percentage of elderly in each area.

A total of 17 districts or neighborhoods (25\%) were randomly selected, allowing a proportionality of elderly in each area. Each district or neighborhood were divided into numbered blocks, and the blocks were randomly selected. Furthermore, the corners of the selected blocks 
were numbers from 1 to 4 , and a new drawn was performed in order to select where the first interview should be performed. After that, the visits were conducted in a clockwise manner until the work set was concluded.

\section{Inclusion and exclusion criteria}

Only home-dwelling elderly, aged 65 to 74 years, were included in the present study. Moreover, they need to be in physical, medical, and mental condition to allow all data collection. If more than one home resident fitted the eligibility criteria, all of them were included. In case of absence in the day of the interview, two other attempts were made before the home were considered excluded. Homes for the aged, commercial homes, and uninhabited households were excluded in the present study.

\section{Clinical examination and interview}

An interview was conducted by the researchers that read all the questions and the possible answers to the elderly. A structured questionnaire was applied, which included sociodemographic and behavioral variables, medical and dental history. This questionnaire was obtained by a block of questions from the PCATool-Brazil21 ${ }^{21}$ Chart 1 shows all the collected variables and the possible answers to each question. Additionally, self-reported halitosis was evaluated by the following question: "Do you have bad breath?", answered by the Likert options: never, rarely, sometimes, often, and always.

The instrument to assess the nutritional status was the Mini Nutritional Assessment $(\mathrm{MNA})^{22}$, which assesses the risk for malnutrition and allows an early nutritional intervention when required. This tool was applied by an experient nutritionist, and according the sum of scores obtained, the patient is classified as normal (eutrophic, MNA > 24 points), at nutritional risk (MNA from 17 to 24 points), or malnourished (MNA $<17$ points). Detailed information about this tool is given elsewhere ${ }^{22}$.

The symptom of temporomandibular joint dysfunction (TMD) was assessed by the Fonseca Anamnestic Index ${ }^{23}$. This index was also applied by the researchers and contains 10 questions about perception of pain in the facial region. To each question, the possible answers are "no", "sometimes" or "yes", attributing 0, 5 or 10 points, respectively. According to the sum of scores ob- tained, the individuals are classified into no TMD symptom ( $\leq 15$ points), mild TMD symptom $(20$ to 40 points), moderate TMD symptom (45 to 65 points), and severe TMD symptom ( $\geq 70$ points). Further information about this index is given elsewhere ${ }^{23}$.

OHRQoL was assessed by the validated version of OHIP-14 instrument for Brazilian samples, which was applied by the researchers ${ }^{24}$. This tool present 14 question about the impact of oral health in the quality of life, under the following domains: function limitation, physical pain, psychological discomfort, physical disability, psychological disability, social disability, and handicap. To all questions, the possible answers are based on the Likert options: never, rarely, sometimes, often, and always.

Oral health examination was performed in order to count the number of present teeth and verify the use and need of dental prosthesis. All teeth were counted except for the third molars. The oral examination was performed with wooden spatula, without artificial illumination and dental mirror.

The individuals were examined and interviewed between July and August 2016 by two teams that included an interviewer, an oral health examiner, and an anthropometric measurement evaluator in each team. Both examiner and evaluator were previously trained and calibrated by the study coordinator. Training consisted of theoretical lectures about the themes, discussion of all questions of the questionnaire, and explanations about how the oral exam and anthropometric measures should be performed. Before the study begin, the questionnaire was applied in a sample of elderly participants not included in the study. Moreover, the anthropometric measures were trained in a sample of elderly from the Physical Education School of the Passo Fundo University. The inter-examiner and intra-examiner reproducibility for the dental examination and anthropometric measures were verified in approximately $5 \%$ of randomly chosen individuals. The examinations were performed twice with two days of interval. Regarding the intra -examiner reproducibility, a kappa coefficient of 1.00 and 0.85 was achieved for need of dental prosthesis and teeth counting, respectively. The weighted kappa values for height (range $\pm 0.01 \mathrm{~m}$ ) and weight (range $\pm 100 \mathrm{~g}$ ) were, respectively, 0.70 and 1.00. Additionally, the inter-examiner reproducibility showed a minimum kappa coefficient of 0.70 for all the previously reported variables. 
Chart 1. Structured questionnaire applied in the present study with questions about sociodemographic characteristics, behavioral variables, medical and dental history.

\begin{tabular}{|c|c|c|c|c|}
\hline Variable & \multicolumn{4}{|c|}{ Answer } \\
\hline \multicolumn{5}{|c|}{ Sociodemographic characteristics } \\
\hline \multicolumn{5}{|l|}{ Age (in years) } \\
\hline Sex & Male ( ) & \multicolumn{3}{|l|}{ Female ( ) } \\
\hline Ethnicity/skin color & White ( ) & Black ( ) Ye & Yellow ( ) & Brown ( ) Indigenous ( ) \\
\hline \multirow[t]{4}{*}{ Level of education } & \multicolumn{3}{|c|}{ Illiterate ( ) } & Only literate ( ) \\
\hline & \multicolumn{3}{|c|}{ Incomplete elementary school ( ) } & Complete elementary school ( ) \\
\hline & \multicolumn{3}{|c|}{ Incomplete high school ( ) } & Complete high school ( ) \\
\hline & \multicolumn{3}{|c|}{ Incomplete tertiary education ( ) } & Complete tertiary education ( ) \\
\hline Marital status & Married ( ) & Single ( ) & & \begin{tabular}{|l|l|} 
Widow ( ) & Divorced ( ) \\
\end{tabular} \\
\hline Are you retired? & \multicolumn{3}{|l|}{ Yes ( ) } & No ( ) \\
\hline \multicolumn{5}{|l|}{ Behavioral variables } \\
\hline Do you smoke? & Yes ( ) & \multicolumn{2}{|l|}{ No ( ) } & I quitted ( ) \\
\hline \multirow[t]{2}{*}{ Do you drink or consume alcohol? } & \multicolumn{2}{|c|}{ Yes, regularly ( ) } & \multicolumn{2}{|c|}{ Yes, just sporadically ( ) } \\
\hline & \multicolumn{2}{|c|}{ No, I stopped drinking ( ) } & \multicolumn{2}{|c|}{ No, I never drink ( ) } \\
\hline \multicolumn{5}{|l|}{ Medical history } \\
\hline Do you have any health problem? & \multicolumn{3}{|l|}{ Yes ( ) } & No ( ) \\
\hline Do you use any everyday medication? & \multicolumn{3}{|l|}{ Yes ( ) } & No ( ) \\
\hline \multicolumn{5}{|l|}{ Dental history } \\
\hline Did you visited a dentist in the last year? & \multicolumn{3}{|l|}{ Yes ( ) } & No ( ) \\
\hline \multicolumn{5}{|l|}{$\begin{array}{l}\text { Do you brush your teeth? How many } \\
\text { times per day? }\end{array}$} \\
\hline Do you use dental floss? & \multicolumn{2}{|l|}{ Yes ( ) } & \multicolumn{2}{|l|}{ No ( ) } \\
\hline
\end{tabular}

\section{Statistical analysis}

A Direct Acyclic Graph (DAG) was constructed, based on all collected variables in order to conduct a proper statistical analysis and also to identify potential colliding bias (Figure 1 ). The dependent variable of the present study was OHRQoL, assessed by OHIP-14. The whole sample was dichotomized into low impact (scores sum $\leq 6$, two thirds of the whole-sample, $\mathrm{n}=$ 198 ) and high impact (scores sum $\geq 7$, one third of the whole-sample, $n=89$ ) on OHRQoL. These values were determined by the tertile of scores sum of OHIP-14 in this sample. We calculated the mean, standard deviation, median of the whole OHIP-14 scores and for each domain. As a non-normal distribution was detected, using the Shapiro-Wilk test, comparison between groups was performed by the Mann-Whitney test.

The independent variables were age, sex, ethnicity/skin color, level of educational, marital status, retirement, health problems, use of medications, alcohol and smoking exposure, access to the dentist in the last 12 months, toothbrushing frequency, use of dental floss, edentulism, tooth loss, need and use of dental prosthesis, self-re- ported halitosis, symptoms of TMD, and nutritional status.

Age was dichotomized into two groups, those with $\leq 69$ years and another with $\geq 70$ years, as the median age of the whole-sample was 69 . Ethnicity/skin color was categorized into withe and non-white. The non-white group was composed by those who refereed themselves as black, yellow, brown, or indigenous. Retirement was dichotomized into yes, for those that reported to be retired, and no, for those that were not retired.

According to the Instituto Brasileiro de Geografia e Estatística (IBGE), the level of education is divided under the following categories: illiterate, only literate, incomplete elementary school, complete elementary school, incomplete high school, complete high school, complete or incomplete higher education, and master or doctorate degree. In the present study, the number of elderly that reported to be illiterate, had complete elementary school, incomplete high school, and incomplete higher education were very low, 17 (5.9\%), 31 (10.8\%), 11 (3.8\%), and 13 (4.5\%) respectively. Therefore, for analytical reasons, these variables had to be grouped, as follow: low level, those individuals with completing up to 
(A)

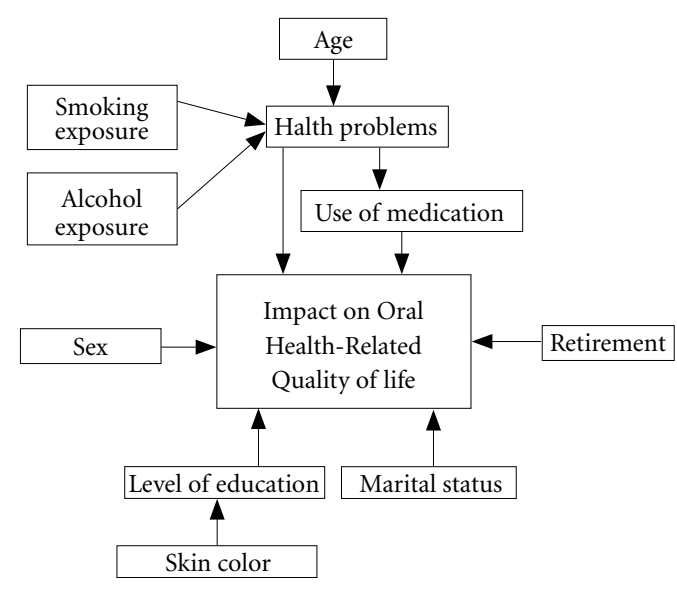

(B)

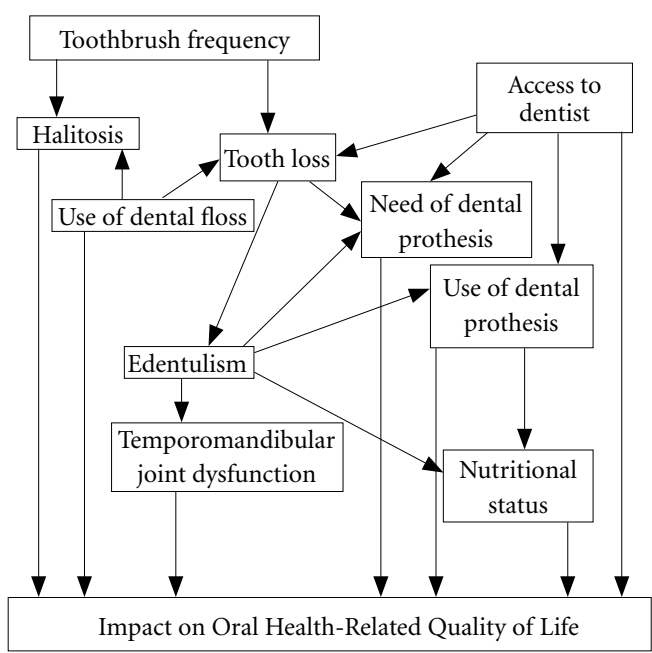

Figure 1. Direct Acyclic Graph (DAG) of all collected variables (sociodemographic, habits, and medical history [a], dental history, dental habits, and nutritional status [b]) and the possible association with the outcome.

elementary school and illiterate; medium level, which included those with incomplete/complete high school; and high level, those with at least incomplete higher education.

Health problems were classified into "no", for those without health problems or those that did not know about their health condition, and "yes" for those with any health problem. The use of medication was divided into two groups, those that used at least one medication and another group that did not report use of medication. Regarding alcohol exposure, the sample was divided into yes, for those that reported to drink regularly or sporadic, and no, for those that never drink or stooped drinking. According to the question: "Did you visited a dentist in the last year?", the sample was dichotomized into yes or no.

The literature reports that individuals that brush their teeth less than two times per day have higher chance of presenting higher oral diseases when compared to those that brush at least two times ${ }^{25}$. For that reason, we dichotomized the frequency of toothbrushing into $<2$ times/day and $\geq 2$ times/day. Need of dental prosthesis was classified into "yes" for those with need of any dental prosthesis, and "no" for those without any dental prosthetic need. Meanwhile, the use of dental prosthesis was categorized into "yes" for elderly wearing a dental prosthesis, and "no" for elderly that did not wear dental prosthesis. Self-reported halitosis was dichotomized into "yes" for those that answered sometimes, often and always to the abovementioned question, and "no" for those that answered never or rarely. TMD symptoms was classified into three groups: no TMD symptoms, mild TMD symptom, and moderate/severe TMD symptom. The MNA tool instrument classifies the individuals into regular nutritional status (eutrophic), at risk of malnutrition, and malnourished. For the present study, the elderly were categorized in eutrophic or at nutritional risk, which included at risk of malnutrition and malnourished.

No continuous variables showed a normal distribution when the Shapiro-Wilk test was used. Association between dependent and independent variables were performed by chi-square and Mann-Whitney test. The level of significance established was 5\%. Moreover, uni- and multivariate analyses were executed by Poisson regression with robust variance. In the multivariate model was included only the independent variables that present a $\mathrm{p}$-value $<0.20$ in the univariate analyses. The maintenance of these variables were determined by the combination of $\mathrm{p}$-value $<0.05$ and analysis of effect changes. Multicollinearity analyses, among the independent variables, were performed and none was observed. The cutoff 
point for multicollinearity was determined as variance inflation factor $<5$ and tolerance $>0.2$. All the data analyses were performed in the software SPPS, version 21.0 (SPSS, version 21.0, IBM Corp., Armonk, NY, USA).

\section{Results}

A total of 287 elderly were interviewed and examined in 260 households, of the 292 households visited (response rate of $89.04 \%$ ). Figure 2 shows the reasons for not participate in the study. A mean age of $69.30(\mathrm{SD} \pm 3.52)$ was demonstrated. It was included $102(35.5 \%)$ and $185(64.5 \%)$ male and females, respectively. Regarding the ethnicity/skin color, 196 (68.3\%) were white and $91(31.7 \%)$ were non-white. Most of the included individuals presented a low level of education ( $\mathrm{n}$ $=190 ; 62.6 \%)$, of which 17 (5.9\%) were illiterate. Approximately, $60 \%$ of the whole sample were married, and $76.3 \%$ were retired. Health problem was detected in $86.4 \%$ of the elderly. Moreover, approximately $42 \%$ reported history of smoking exposure.

The mean scores of OHIP-14 was 5.92 \pm 8.54 . In the present study, the tertile of OHIP-14 scores sum was used to dichotomize the sample. Therefore, two groups were created: those with low impact on OHRQoL (scores sum $\leq 6 ; \mathrm{n}=198$, 69.0\%; mean: $1.72 \pm 1.94)$ and those with high impact on OHRQoL (scores sum $\geq 7 ; n=89,31.0 \%$; mean: 15.24 \pm 10.04$)$. The comparison between groups showed that the mean scores of OHIP-14 were significantly different $(\mathrm{p}<0.001)$ (Table 1 ). Additionally, the group with the highest impact on OHRQoL presented significantly higher scores in all seven OHIP-14 domains (Table 1).

It was demonstrated a statistically significant association with impact on OHRQoL and the following independent variables: smoking exposure $(\mathrm{p}=0.026)$, need of dental prosthesis (0.009), mild and moderate/severe TMD symptoms $(\mathrm{p}<0.001)$, and nutritional status $(\mathrm{p}=$ 0.005) (Table 1). Other variables did not show significant association with impact on OHRQoL,

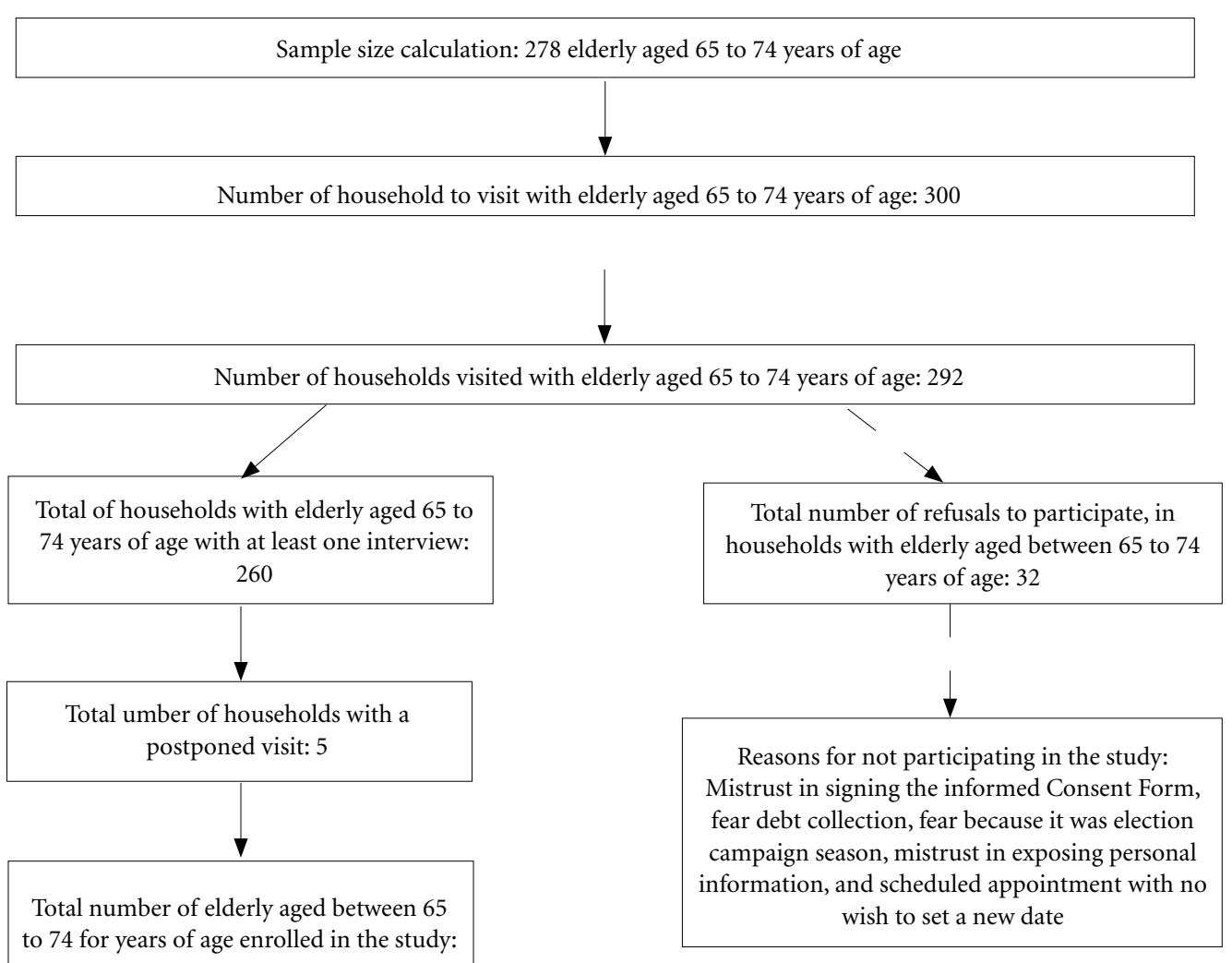

Figure 2. Flowchart of the study. 
Table 1. OHIP-14 total scores and scores per domain in different groups. Demographic characteristics of the sample, frequency distribution and univariate model associating independent variables and impact on the oral health-related quality of life, among elderly aged 65 to 74 years of age, are reported (Cruz Alta, Brazil, 2016).

\begin{tabular}{|c|c|c|c|c|c|}
\hline \multicolumn{6}{|c|}{ OHIP-14 questionnaire } \\
\hline \multicolumn{2}{|c|}{ Variables } & Low impact & High impact & Whole-sample & P-value \\
\hline \multicolumn{2}{|l|}{ Total score } & $1.72 \pm 1.94(1.0)$ & $15.25 \pm 10.04(12.0)$ & $5.91 \pm 8.54(3.0)$ & $<0.001^{\star}$ \\
\hline \multicolumn{2}{|c|}{ Functional limitation } & $0.22 \pm 0.69(0.0)$ & $1.89 \pm 2.37(1.0)$ & $0.74 \pm 1.63(0.0)$ & $<0.001^{\star}$ \\
\hline \multicolumn{2}{|l|}{ Physical pain } & $0.63 \pm 1.02(0.0)$ & $2.84 \pm 2.22(3.0)$ & $1.32 \pm 1.81(0.0)$ & $<0.001^{\star}$ \\
\hline \multicolumn{2}{|c|}{ Psychological discomfort } & $0.38 \pm 0.93(0.0)$ & $3.36 \pm 2.33(4.0)$ & $1.30 \pm 2.04(0.0)$ & $<0.001^{\star}$ \\
\hline \multicolumn{2}{|l|}{ Physical disability } & $0.27 \pm 0.73(0.0)$ & $1.98 \pm 2.30(2.0)$ & $0.80 \pm 1.62(0.0)$ & $<0.001^{\star}$ \\
\hline \multicolumn{2}{|c|}{ Psychological disability } & $0.11 \pm 0.44(0.0)$ & $2.40 \pm 2.15(2.0)$ & $0.82 \pm 1.64(0.0)$ & $<0.001^{*}$ \\
\hline \multicolumn{2}{|l|}{ Social disability } & $0.04 \pm 0.25(0.0)$ & $1.09 \pm 1.89(0.0)$ & $0.36 \pm 1.17(0.0)$ & $<0.001^{\star}$ \\
\hline \multicolumn{2}{|l|}{ Handicap } & $0.08 \pm 0.39(0.0)$ & $1.69 \pm 2.06(1.0)$ & $0.57 \pm 1.40(0.0)$ & $<0.001^{\star}$ \\
\hline \multicolumn{6}{|c|}{ Sample characteristics and association with OHRQoL } \\
\hline \multicolumn{2}{|c|}{ Variables } & Low impact & High impact & $\begin{array}{c}\text { Prevalence ratio } \\
(95 \% \mathrm{CI})\end{array}$ & P-value \\
\hline \multirow[t]{2}{*}{ Age (years) } & $\leq 69-\mathrm{n}(\%)$ & $99(50.0)$ & $54(60.7)$ & Ref. & \\
\hline & $\geq 70-\mathrm{n}(\%)$ & $99(50.0)$ & $35(39.3)$ & $0.74(0.52-1.06)$ & 0.098 \\
\hline \multirow[t]{2}{*}{ Sex } & Male - n (\%) & $68(34.3)$ & $34(38.2)$ & Ref. & \\
\hline & Female - n (\%) & $130(65.7)$ & $55(61.8)$ & $0.89(0.63-1.27)$ & 0.525 \\
\hline \multirow{2}{*}{$\begin{array}{l}\text { Ethnicity/skin } \\
\text { color }\end{array}$} & White - n (\%) & $133(67.2)$ & $63(70.8)$ & Ref. & \\
\hline & Non-white - n (\%) & $65(32.8)$ & $26(29.2)$ & $0.89(0.61-1.30)$ & 0.547 \\
\hline \multirow{3}{*}{$\begin{array}{l}\text { Level of } \\
\text { education }\end{array}$} & Low $-\mathrm{n}(\%)$ & $125(63.1)$ & $65(73.0)$ & Ref. & \\
\hline & Medium - n (\%) & $36(18.2)$ & $16(18.0)$ & $0.90(0.57-1.42)$ & 0.646 \\
\hline & High - n (\%) & $37(18.7)$ & $8(9.0)$ & $0.52(0.27-1.00)$ & 0.051 \\
\hline \multirow[t]{4}{*}{ Marital status } & Married - n (\%) & $116(58.6)$ & $49(55.1)$ & Ref. & \\
\hline & Single - n (\%) & $22(11.1)$ & $9(10.1)$ & $0.98(0.54-1.78)$ & 0.941 \\
\hline & Divorced - n (\%) & $18(9.1)$ & $14(15.7)$ & $1.47(0.93-2.33)$ & 0.097 \\
\hline & Widow - n (\%) & $42(21.2)$ & $17(19.1)$ & $0.97(0.61-1.54)$ & 0.899 \\
\hline \multirow[t]{2}{*}{ Retired } & Yes $-\mathrm{n}(\%)$ & $46(23.2)$ & $22(24.7)$ & Ref. & \\
\hline & No - n (\%) & $152(76.8)$ & $67(75.3)$ & $1.06(0.71-1.57)$ & 0.783 \\
\hline \multirow[t]{2}{*}{ Health problem } & Yes - n (\%) & $172(86.9)$ & $76(85.4)$ & Ref. & \\
\hline & No $-n(\%)$ & $26(13.1)$ & $13(14.6)$ & $1.08(0.67-1.76)$ & 0.732 \\
\hline \multirow{2}{*}{$\begin{array}{l}\text { Use of } \\
\text { medication }\end{array}$} & Yes - n (\%) & $168(84.8)$ & $69(77.5)$ & Ref. & \\
\hline & No - n (\%) & $30(15.2)$ & $20(22.5)$ & $1.37(0.93-2.04)$ & 0.113 \\
\hline \multirow{3}{*}{$\begin{array}{l}\text { Smoking } \\
\text { exposure }\end{array}$} & Smoker - n (\%) & $21(10.6)$ & $14(15.7)$ & Ref. & \\
\hline & Former smoker - n (\%) & $52(26.3)$ & $34(38.2)$ & $0.99(0.61-1.60)$ & 0.962 \\
\hline & Never smoker - n (\%) & $125(63.1)$ & $41(46.1)$ & $0.62(0.38-1.00)$ & 0.051 \\
\hline \multirow[t]{2}{*}{ Alcohol exposure } & Yes - n (\%) & $77(38.9)$ & $33(37.1)$ & Ref. & \\
\hline & No $-n(\%)$ & $121(61.1)$ & $56(62.9)$ & $1.06(0.74-1.51)$ & 0.771 \\
\hline Access to the & Yes $-\mathrm{n}(\%)$ & $99(50.0)$ & $36(40.40)$ & Ref. & \\
\hline $\begin{array}{l}\text { dentist in the last } \\
12 \text { months }\end{array}$ & No - n (\%) & $99(50.0)$ & $53(59.6)$ & $1.31(0.92-1.86)$ & 0.138 \\
\hline Toothbrushing & $<2$ times/day $-\mathrm{n}(\%)$ & $38(19.2)$ & $23(25.8)$ & Ref. & \\
\hline frequency & $\geq 2$ times/day $-\mathrm{n}(\%)$ & $160(80.8)$ & $66(74.2)$ & $0.78(0.53-1.13)$ & 0.189 \\
\hline Use of dental & Yes - n (\%) & $67(33.8)$ & $20(22.5)$ & Ref. & \\
\hline floss & No $-\mathrm{n}(\%)$ & $131(66.2)$ & $69(77.5)$ & $1.50(0.98-2.31)$ & 0.064 \\
\hline Edentulism & Yes $-\mathrm{n}(\%)$ & $60(30.3)$ & $26(29.2)$ & Ref. & \\
\hline & No $-n(\%)$ & $138(69.7)$ & $63(70.8)$ & $1.04(0.71-1.52)$ & 0.853 \\
\hline Tooth loss & Mean \pm SD & $19.31 \pm 8.69$ & $20.54 \pm 7.00$ & $1.01(0.99-1.04)$ & 0.211 \\
\hline Wear dental & Yes - n (\%) & $171(86.4)$ & $69(77.5)$ & Ref. & \\
\hline prosthesis & No $-n(\%)$ & $27(13.6)$ & $20(22.5)$ & $1.48(1.01-2.18)$ & 0.047 \\
\hline Need of dental & Yes - n (\%) & $74(37.4)$ & $48(53.9)$ & Ref. & \\
\hline prosthesis & No $-\mathrm{n}(\%)$ & $124(62.6)$ & $41(46.1)$ & $0.63(0.45-0.89)$ & 0.009 \\
\hline
\end{tabular}


Table 1. OHIP-14 total scores and scores per domain in different groups. Demographic characteristics of the sample, frequency distribution and univariate model associating independent variables and impact on the oral health-related quality of life, among elderly aged 65 to 74 years of age, are reported (Cruz Alta, Brazil, 2016).

\begin{tabular}{lccccc}
\hline Self-reported & Yes $-\mathrm{n}(\%)$ & $68(34.3)$ & $41(46.1)$ & Ref. & \\
halitosis & No $-\mathrm{n}(\%)$ & $130(65.7)$ & $48(53.9)$ & $0.72(0.51-1.01)$ & 0.056 \\
\hline TMD symptom & No TMD - n (\%) & $108(54.5)$ & $21(23.6)$ & Ref. & \\
& Mild TMD - n (\%) & $71(35.9)$ & $49(55.1)$ & $2.51(1.61-3.92)$ & $<0.001$ \\
& Moderate/severe & $19(9.6)$ & $19(21.3)$ & $3.07(1.86-5.09)$ & $<0.001$ \\
& TMD - n (\%) & & & \\
Nutritional status & Eutrophic - n (\%) & $113(57.1)$ & $35(39.3)$ & Ref. & \\
& At nutritional risk/ & $85(42.9)$ & $54(60.7)$ & $1.64(1.15-2.35)$ & 0.006
\end{tabular}

${ }^{\star}$ Mann-Whitney test for the comparison between low and high impact groups; SD: standard deviation; TMD: temporomandibular joint dysfunction.

Table 2. Multivariate model associating independent variables and impact on the oral health-related quality of life among the elderly aged 65 to 74 years (Cruz Alta, Brazil, 2016).

\begin{tabular}{llcc}
\hline & Variables & Prevalence ratio $(\mathbf{9 5 \%} \mathbf{C I})$ & P-value \\
\hline Marital status & Married & Ref. & \\
& Single & $0.965(0.574-1.621)$ & 0.892 \\
& Divorced & $1.770(1.179-2.659)$ & 0.006 \\
\multirow{5}{*}{ Use of dental floss } & Widow & $0.972(0.613-1.539)$ & 0.902 \\
\multirow{5}{*}{ Need of dental prosthesis } & Yes & Ref. & 0.041 \\
& No & $1.538(1.017-2.327)$ & \\
TMD symptom & No & Ref. & 0.004 \\
& No TMD & $0.613(0.441-0.852)$ & $<0.001$ \\
& Mild TMD & Ref. & $<0.001$ \\
\hline
\end{tabular}

In the initial multivariate model, the following variables were included: age, level of education, marital status, use of medications, smoking exposure, access to the dentist in the last 12 months, toothbrushing frequency, use of dental floss, use of dental prosthesis, need of dental prosthesis, halitosis, TMD symptoms, and nutritional status.

such as level of education $(\mathrm{p}=0.101)$, sex $(\mathrm{p}=$ $0.528)$, health problems $(\mathrm{p}=0.736)$, access to the dentist in the last 12 months $(\mathrm{p}=0.134)$.

Table 1 also shows the univariate analysis of the association between impact on OHRQoL and the independent variables. Elderly that did not wear dental prosthesis presented 48\% $(\mathrm{p}=0.047)$ higher prevalence ratio (PR) of having higher impact on OHRQoL in comparison to those the wear dental prosthesis. Conversely, those that did not need dental prosthesis presented 37\% lower PR of having higher impact on OHRQoL ( $\mathrm{p}=$ 0.009 ). Mild or moderate/severe TMD symptoms increased the PR of having higher impact on OHRQoL in $2.50(\mathrm{p}<0.001)$ and 3.07 ( $\mathrm{p}<$ 0.001 ) times, respectively, in comparison to those with no TMD symptom. Additionally, elderly at nutritional risk (at risk of malnutrition or malnourished) presented a PR 64\% higher, than those considered eutrophic, of having higher impact on OHRQoL.

In the initial multivariate model, the following variables were included: age, level of education, marital status, use of medication, smoking exposure, access to the dentist in the las 12 months, toothbrushing frequency, use of dental floss, use of dental prosthesis, need of dental prosthesis, halitosis, TMD symptoms, and nutritional status. In the final multivariate model, it remained significantly associated with impact on OHRQoL the following variables: material status, use of dental floss, need of dental prosthesis, and TMD symptoms (Table 2). Elderly that were divorced or did not use dental floss presented 
a PR of $77 \%(p=0.006)$ and 53\% $(p=0.041)$, respectively, of having a higher impact on OHRQoL. The comparisons were made with married elderly and with dental floss users, respectively. Moreover, those that presented mild or moderate/severe TMD symptoms showed, respectively, $2.53(\mathrm{p}<0.001)$ and $2.84(\mathrm{p}<0.001)$ higher PR ratio of being in the groups of higher impact on OHRQoL when compared to those with no TMD symptom.

Conversely, those that did not need rehabilitation with dental prosthesis presented a lower impact on OHRQoL. Elderly that did not need dental prosthesis showed a PR of $38.7 \%$ lower of having higher impact on OHRQoL in comparison to those that need oral rehabilitation ( $\mathrm{p}=$ $0.004)$.

\section{Discussion}

The present study evaluated the association between impact on OHRQoL in the elderly of a Brazilian southern city. This evaluation is very important because this age stratum in increasing significantly throughout the decades. Furthermore, these results may help the public health policies for this cycle of life. A mean OHIP-14 demonstrated in the present study was 5.92 . Divorced marital status, absence of dental floss use, need of dental prosthesis, and TMD symptoms are associated with higher impact on OHRQoL.

Overall, the present study demonstrated a low impact on OHRQoL in the elderly. This result is similar to other studies conducted in Brazil that showed means OHIP-14 scores of $3.67^{26}$ and $6.18^{27}$. Equivalent results were detected in studies conducted in other countries. A study performed in the United Kingdom showed a mean OHIP-14 scores of 2.95 in the elderly aged 65 to 75 years $^{28}$. The literature also reports impacts on OHRQoL slightly higher, with mean scores of OHIP-14 $8.88^{12}$ and $10.21^{29}$, which is still considered a low impact.

The low impact on OHRQoL demonstrated in the present study may be explained by the adaptability of individuals to situations or events of their daily lives. The literature shows that most of the elderly consider their chewing ability and oral health adequate, even when they need dental treatment or when they wear dental prosthesis ${ }^{27}$. The cultural factor may be taken into consideration because tooth loss is considered normal, as long as the natural aging process is occurring 5 . Furthermore, chronic non-communicable diseases are very common in those individuals, which may explain the little impact attributed to the OHRQoL despite their actual oral condition. The absence of acute pain, even in the presence of chronic pain, may trigger an adaptability, leading the elderly to a less worry about their condition ${ }^{28}$. In this sense, several elderly that wear unsatisfactory dental prosthesis, that present several tooth loss or that have caries and periodontal diseases may not feel the impact on OHRQoL.

The marital status was significantly associated with higher impact on OHRQoL in the present study. In fact, divorced elderly presented a higher impact on OHRQoL in comparison to married elderly. This result is in accordance with other studies that demonstrated that a solitary situation may impair the quality of life $\mathrm{e}^{5,6}$. Loneliness among elderly may be due to widowhood, divorce or by single individuals, and it is assumed that may increase in the next years, causing serious impact in our society.

Variables related to oral health were also associated with higher impact on OHRQoL. Those that did not need dental prosthesis presented a lower impact on OHRQoL. Similarly, the literature reports that those in need of dental prosthesis present significantly higher mean OHIP scores in comparison to those that did not need dental prosthesis $^{30,31}$.The use of dental floss was associated with lower impact on OHRQoL in the present study. Overall, the better oral hygiene practices are associated with improved oral health conditions. In fact, several studies demonstrated that the elderly with poor oral health, mainly dental caries, present higher impact on OHRQoL ${ }^{28,32}$.

Elderly with mild or moderate/severe TMD symptoms presented, respectively, 2.5 and 2.8 higher prevalence ratio of worst OHRQoL. These results are in accordance with other study that demonstrated that pain, caused by TMD, is associated with higher OHRQoL when compared to those with no TMD symptom ${ }^{33}$. The issues involving TMDs are controversial because their extensions and severity are not fully understood. It must be highlighted that many TMD related problems are associated with the modern way of life and its consequences. Nonetheless, this topic is little explored in the literature.

In the present study, sex was not associated with higher impact on OHRQoL. However, other studies demonstrated a tendency of women presenting the worst quality of life ${ }^{26,34}$. Similarly to sex, smoking exposure was not associated with higher OHRQoL in the final multivariate model. On the other hand, the literature supports this association $^{7}$. 
This is a representative study of the elderly inhabitants of Cruz Alta, Rio Grande do Sul, Brazil. One of the advantages of the present study is the sampling strategy, which used a cluster probabilistic sample. A higher external validity may be attributed for the present study, especially because the sex, ethnicity/skin color, and level of education distribution were similar to the one found in Cruz Alta ${ }^{18}$. Other advantages are the trained and calibrated examiners for data collections, which increase the validity of the present study. Conversely, this study presents some limitations: its cross-sectional design, which does not allow temporality between the outcome and the independent variables. Moreover, this study only counted the number of present teeth. The absence of clinical evaluation for dental caries, periodontal diseases and TMD may be other limitations. The literature already reported the higher impact on OHRQoL in individuals with chronic periodontitis ${ }^{35}$ and higher Decayed, Missing, Filling Index ${ }^{36}$. Despite of that, the study design allows data generalization for comparisons with other home-based studies with representative samples.

The relationship of human aging and oral health must take into consideration several aspects, such as biological, physical, psychological, socioeconomic, among others ${ }^{37}$. The relationship between quality of life, oral health conditions, and level of education is important to planning the public health policies for this cycle of life in the next decades.

\section{Conclusions}

It was concluded that a low impact on OHRQoL was detected among the elderly. Higher impact on the OHRQoL was found in divorced, nonusers of dental floss, and those with TMD symptoms. On the other hand, no need of dental prosthesis presented lower impact on OHRQoL.

\section{Collaborations}

J Colaço helped in data collection, interpreted the data, wrote the manuscript, revised the literature, and approved the final version of the manuscript. FWMG Muniz helped in the study design, performed the data analysis, wrote the manuscript, and approved the final version of the manuscript. D Peron helped in data collection, literature review and writing the manuscript, and approved the final version of the manuscript. MG Marostega helped in data collection, literature review and writing the manuscript, and approved the final version of the manuscript. JJ Dias helped in data collection, literature review and writing the manuscript, and approved the final version of the manuscript. CK Rösing helped in the study designed, writing the manuscript and approved the final version of the manuscript. PRG Colussi designed the study, helped in data collection, revised the literature, wrote the manuscript, and approved the final version of the manuscript. 


\section{Acknowledgements}

This study was self-funded and the authors have stated explicitly that there are no conflicts of interest in connection with this article. This study was conducted in a Graduate Program supported by CAPES, Brazil.

\section{References}

1. Kossioni AE, Hajto-Bryk J, Maggi S, McKenna G, Petrovic M, Roller-Wirnsberger RE, Schimmel M, Tamulaitienè M, Vanobbergen J, Müller F. An Expert Opinion from the European College of Gerodontology and the European Geriatric Medicine Society: European Policy Recommendations on Oral Health in Older Adults. J Am Geriatr Soc 2018; 66(3):609-613.

2. Kotzer RD, Lawrence HP, Clovis JB, Matthews DC. Oral health-related quality of life in an aging Canadian population. Health Qual Life Outcomes 2012; 10:50.

3. Brasil. Instituto Brasileiro de Geografia e Estatística (IBGE). Relações entre as Alterações Históricas na Dinâmica Demográfica Brasileira e os Impactos Decorrentes do Processo de Envelhecimento da População [Internet]. 2011 [cited 2017 May 05]. Available in: http://www.ibge.gov.br/home/estatistica/populacao/ alteracoes_e_impactos/default.shtm

4. Sischo L, Broder HL. Oral health-related quality of life: what, why, how, and future implications. J Dent Res 2011; 90(11):1264-1270.

5. Teixeira MF, Martins AB, Celeste RK, Hugo FN, Hilgert JB. Association between resilience and quality of life related to oral health in the elderly. Rev Bras Epidemiol 2015; 18(1):220-233.

6. Rouxel P, Heilmann A, Demakakos P, Aida J, Tsakos G, Watt RG. Oral health-related quality of life and loneliness among older adults. Eur J Ageing 2017;14(2):101-109.

7. Gabardo MC, Moysés SJ, Moysés ST, Olandoski M, Olinto MT, Pattussi MP. Social, economic, and behavioral variables associated with oral health-related quality of life among Brazilian adults. Cien Saude Colet 2015; 20(5):1531-1540.

8. Brasil. Ministério da Saúde (MS). Pesquisa Nacional de Saúde Bucal: Resultados principais. Brasília: MS; 2012.

9. Bortoluzzi MC, Traebert J, Lasta R, Da Rosa TN, Capella DL, Presta AA. Tooth loss, chewing ability and quality of life. Contemp Clin Dent 2012; 3(4):393-397.

10. CG, Cascaes AM, Silva AE, Seerig LM, Nascimento GG, Demarco FF. Edentulism, Severe Tooth Loss and Lack of Functional Dentition in Elders: A Study in Southern Brazil. Braz Dent J 2016; 27(3):345-352.

11. Santos CM, Martins AB, Marchi RJ, Hilgert JB, Hugo FN, Padilha DM. Assessing changes in oral health-related quality of life and its factors in community-dwelling older Brazilians. Gerodontology 2013; 30(3):176-186.

12. Sáez-Prado B, Haya-Fernández MC, Sanz-García MT. Oral health and quality of life in the municipal senior citizen's social clubs for people over 65 of Valencia, Spain. Med Oral Patol Oral Cir Bucal 2016; 21(6):e672-e678

13. Edman K, Holmlund A, Nordström B, Öhrn K. Attitudes to dental care, Sweden 2003-2013, and clinical correlates of oral health-related quality of life in 2013. Int J Dent Hyg 2018; 16(2):257-266.

14. Sheng X, Xiao X, Song X, Qiao L, Zhang X, Zhong H. Correlation between oral health and quality of life among the elderly in Southwest China from 2013 to 2015. Medicine (Baltimore) 2018; 97(21):e10777. 
15. Tsakos G, Steele JG, Marcenes W, Walls AW, Sheiham A. Clinical correlates of oral health-related quality of life: evidence from a national sample of British older people. Eur J Oral Sci 2006; 114(5):391-395.

16. Jenei Á, Sándor J, Hegedüs C, Bágyi K, Nagy L, Kiss C, Szabó G, Márton IJ. Oral health-related quality of life after prosthetic rehabilitation: a longitudinal study with the OHIP questionnaire. Health Qual Life Outcomes 2015; 13:99.

17. Azevedo MS, Correa MB, Azevedo JS, Demarco FF. Dental prosthesis use and/or need impacting the oral health-related quality of life in Brazilian adults and elders: Results from a National Survey. J Dent 2015; 43(12):1436-1441.

18. Brasil. Instituto Brasileiro de Geografia e Estatística (IBGE). Ministério do Planejamento, Orçamento e Gestão. Censo Demográfico 2010: Características da população e domicílios - resultados gerais. Rio de Janeiro: IBGE; 2011.

19. Brasil. Ministério da Saúde (MS). DATASUS. Índice de gini da renda domiciliar per capita - Rio Grande do Sul [Internet]. 2010 [cited 2017 Nov 16]. http://tanet. datasus.gov.br/cgi/ibge/cnv/ginirs.def

20. Stoffel L, Muniz FW, Colussi PR, Rösing CK, Colussi EL. Nutritional assessment and associated factors in the elderly: a population-based cross-sectional study. Nutrition 2018; 55-56:104-110.

21. Brasil. Ministério da Saúde (MS). Manual do Instrumento de Avaliação da Atenção Primária à Saúde: PCATool-Brasil. Brasília: MS; 2010.

22. Vellas B, Guigoz Y, Garry PJ, Nourhashemi F, Bennahum D, Lauque S, JL Albarede. The Mini Nutritional Assessment (MNA) and its use in grading the nutritional state of elderly patients. Nutrition 1999; 15(2):116-122.

23. Fonseca D, Bonfante G, Valle A, Freitas S. Diagnóstico pela anamnese da disfunção craniomandibular. Rev Gaúcha Odontol 1994; 42(1):23-28.

24. Oliveira BH, Nadanovsky P. Psychometric properties of the Brazilian version of the Oral Health Impact Profile-short form. Community Dent Oral Epidemiol 2005; 33(4):307-314.

25. Kumar S, Tadakamadla J, Johnson NW. Effect of Toothbrushing Frequency on Incidence and Increment of Dental Caries: A Systematic Review and Meta-Analysis. J Dent Res 2016; 95(11):1230-1236.

26. Rigo L, Basso K, Pauli J, Cericato GO, Paranhos LR, Garbin RR. Satisfaction with life, dental experience and self-perception of oral health among the elderly. Cien Saude Colet 2015; 20(12):3681-3688.

27. Martins AM, Jones KM, Souza JG, Pordeus IA. Association between physical and psychosocial impacts of oral disorders and quality of life among the elderly. Cien Saude Colet 2014; 19(8):3461-3478.

28. Masood M, Newton T, Bakri NN, Khalid T, Masood Y. The relationship between oral health and oral health related quality of life among elderly people in United Kingdom. J Dent 2017; 56:78-83.
29. Batista MJ, Lawrence HP, de Sousa MaL. Impact of tooth loss related to number and position on oral health quality of life among adults. Health Qual Life Outcomes 2014; 12:165.

30. Biazevic MG, Michel-Crosato E, Iagher F, Pooter CE, Correa SL, Grasel CE. Impact of oral health on quality of life among the elderly population of Joaçaba, Santa Catarina, Brazil. Braz Oral Res 2004; 18(1):85-91.

31. León S, Bravo-Cavicchioli D, Giacaman RA, Correa -Beltrán G, Albala C. Validation of the Spanish version of the oral health impact profile to assess an association between quality of life and oral health of elderly Chileans. Gerodontology 2016; 33(1):97-105.

32. Skośkiewicz-Malinowska K, Noack B, Kaderali L, Malicka B, Lorenz K, Walczak K, Weber MT, Mendak-Ziółko M, Hoffmann T, Ziętek M, Walter M, Kaczmarek U, Hannig C, Radwan-Oczko M, Raedel M. Oral Health and Quality of Life in Old Age: A Cross-Sectional Pilot Project in Germany and Poland. Adv Clin Exp Med 2016; 25(5):951-959.

33. Gillborg S, Åkerman S, Lundegren N, Ekberg EC. Temporomandibular Disorder Pain and Related Factors in an Adult Population: A Cross-Sectional Study in Southern Sweden. J Oral Facial Pain Headache 2017; 31(1):37-45.

34. Motallebnejad M, Mehdizadeh S, Najafi N, Sayyadi F. The evaluation of oral health-related factors on the quality of life of the elderly in Babol. Contemp Clin Dent 2015; 6(3):313-317.

35. He S, Wei S, Wang J, Ji P. Chronic periodontitis and oral health-related quality of life in Chinese adults: A population-based, cross-sectional study. J Periodontol 2018; 89(3):275-284.

36. Drachev SN, Brenn T, Trovik TA. Oral Health-Related Quality of Life in Young Adults: A Survey of Russian Undergraduate Students. Int J Environ Res Public Health 2018; 15(4):719.

37. Deponti R, Acosta M. Compreensão dos idosos sobre os fatores que influenciam no envelhecimento saudável. Estud Interdisciplinares Envelhecimento 2010; 15(1):31-50.

Article submitted 06/07/2018

Approved 27/03/2019

Final version submitted 29/03/2019 